\title{
Implementation of Beam Matching Concept for the New Installed Elekta Precise Treatment System Medical LINACs in Indonesia
}

\author{
O. A. Firmansyah ${ }^{1 *}$, A. F. Firmansyah ${ }^{1}$, S. I. Sunaryati ${ }^{1}$, M. M. Putri ${ }^{2}$, A. R. Setiadi ${ }^{2}$, \\ O. A. Akbar ${ }^{2}$, V. Arif ${ }^{2}$, C. Amelia ${ }^{3}$ \\ ${ }^{I}$ Center for Radiation Safety Technology and Metrology, National Nuclear Energy Agency (BATAN), \\ Jl. Lebak Bulus Raya No. 49, Jakarta 12440, Indonesia \\ ${ }^{2}$ PT. Besindo Medi Prima, The Belleza Permata Hijau, Jakarta 12210, Indonesia \\ ${ }^{3}$ Sanglah General Hospital, Jl. Diponegoro Dauh Puri Klod, Bali 80113, Indonesia
}

\section{ARTICLE INFO}

Article history:

Received 31 March 2020

Received in revised form 31 May 2021

Accepted 7 June 2021

Keywords:

Beam matching

PDD

Profile

Linac

\begin{abstract}
A B S T R A C T
A concept of radiation beam matching of some medical linear accelerators (LINACs) that have identical characteristics of the models, radiation quality, and multileaf collimator features may be implemented as long as the manufacturer provides complete specifications so that a Treatment Planning System (TPS) can be used for many beam-matched LINACs. This paper describes a preliminary study on the implementation of the beam matching concept for five units Elekta Precise Treatment System LINACs that have recently been installed in Indonesia. The beam matching criteria were based on the percentage depth dose (PDD) and beam profile for photon and electron beams. Dosimetry measurements were carried out by using an SNC 125 ionization chamber of $0.125 \mathrm{~cm}^{3}$ in volume, PTW Pinpoint 3D of $0.016 \mathrm{~cm}^{3}$ in volume, and PTW Farmer Chamber of $0.6 \mathrm{~cm}^{3}$ in volume. The results indicated that the $\mathrm{PDD}_{10}$ of 6 and $10 \mathrm{MV}$ photon beams among installed five units LINACs have excellent compatibility each others with a maximum deviation of less than $0.4 \%$, while the maximum deviation for dose depth of $80 \%\left(\mathrm{R}_{80}\right)$ for the electron beams with nominal energies of $4,6,8,10,15$ and $18 \mathrm{MeV}$ is $1 \mathrm{~mm}$. The measurement results for the flatness profile were less than $6 \%$, and symmetry profiles were less than $3 \%$. It also outlines the determination of the absorbed dose to water under reference conditions. The results of the calibration of output doses show that the absorbed dose in the water was $1 \mathrm{cGy} \approx 1 \mathrm{MU}$. The data obtained from measurements for each LINAC conform with the requirements of the beam matching process set by the manufacturer.
\end{abstract}

(C) 2021 Atom Indonesia. All rights reserved

\section{INTRODUCTION}

In principle, radiotherapy uses ionizing radiation to kill cancer cells by irradiating a certain quantity of radiation dose to tumor volume while minimizing the effects of radiation on healthy tissue. Accuracy of the radiation doses delivered to patients should not exceed $\pm 5 \%$ [1] When the radiation dose exceeds $5 \%$, it may cause an increase of 10-20\% tumor control probability and a 20-30 \% probability of healthy tissue being affected. For this reason, it is necessary to make accurate plan in delivering

${ }^{*}$ Corresponding author

E-mail address: oafirmansyah@gmail.com

DOI: https://doi.org/10.17146/aij.2021.1041 radiation doses by making every steps of radiotherapy process have a small uncertainty [2].

Normally, the steps of installation, acceptance test procedure (ATP), and beam data collection (BDC) of a medical linear accelerator (LINACs) take about three months. Thus, in order to shorthen the ATP and BDC processes, one of the solutions is the implementation of the beam matching concept. In general, the beam matching concept can be implemented by managing the radiation beam quality close to the reference LINAC [3].

For implementing the beam matching concept, each manufacturer has its own procedure. As an example, for Varian LINAC, the maximum depth $\left(D_{\max }\right)$ in the central axis of the photon beam have to 
be in the range of $\pm 1.5 \mathrm{~mm}$ and the deviation for the $\mathrm{PDD}_{10}$ have to be in the range of $\pm 0.5 \%$. For radiation beam profiles at a depth of $10 \mathrm{~cm}\left(\mathrm{D}_{10}\right)$ have to be in the range of $\pm 2 \%$. The output at maximum depth $\left(D_{\max }\right)$ have to be in the range of $\pm 1 \%$ of the average value [4]

Meanwhile, the Elekta LINAC only uses the $\mathrm{PDD}_{10}$, which have to be fit within a range of $\pm 1 \%$, and the beam profile at $10 \times 10 \mathrm{~cm}$ and $30 \times 30 \mathrm{~cm}$ at a $\mathrm{D}_{10} \mathrm{~cm}$ have to be within the range of $\pm 2 \%$. Other manufacturers also have their own criteria in accordance to their LINAC specifications.

There is a program provided by Elekta LINAC manufacturer as a guideline for implementation of the beam matching concept called Accelerated Go Live (AGL). The AGL can be used as a protocol for the beam matching process. By using the AGL program, vendors can speed up the acceptance and commissioning processes for beam modeling of the Monaco Treatment Planning System ${ }^{\mathrm{TM}}$ software, thus enabling faster clinical use after technical acceptance. The time needed for the process of matching the model is only about 5-7 days, in contrast to the ideal conditions, which take 3-4 weeks.

Several authors have reported successful processes of beam matching that can be used as references for beam matching implementation of LINACs that have identical characteristics [5]. Ehab et al. [4] have successfully implemented the beam matching concept to two Siemens Oncor medical LINACs at Children's Cancer Hospital in Cairo, Egypt. Janhavi et al. [6] have also implemented the concept of beam matching to two Siemens Oncor medical LINACs. Zhengzheng Xu [7] confirmed that their institution have used the beam matching concept to three Elekta LINACs, namely Elekta InfinityTM, Elekta Sinergy PlatformTM, and Elekta Versa HDTM. Based on these experiences, the successful implementation of the beam matching concept has been realized by adjusting the dosimetric parameters between a LINACs and the reference LINAC with a deviation range of $\pm 1 \%$.

By implementing the beam matching concept, if something unintended happens to a LINAC or TPS software, patients can be referred to other radiotherapy facilities that have successfully beammatched without having to re-plan patient irradiation [7]. For the case of a radiotherapy facility that has several LINACs, the implementation of beam matching concept is certainly an advantage as the operation of the radiotherapy services can be maintained as well as time-saving.

By the end of 2019, five hospitals in Indonesia have installed the same model LINACs of Elekta Precise Treatment System ${ }^{\mathrm{TM}}$. This Elekta
Precise Treatment linear accelerator has 6 and $10 \mathrm{MV}$ photon beam as well as electron beam with nominal energies of $4,6,8,10,12,15$, and $18 \mathrm{MeV}$. These LINACs use the same Monaco Treatment Planning System (TPS) software.

The Elekta Precise Treatment System medical LINACs were installed at the Sanglah Central General Hospital in Denpasar, Bali, the Central General Hospital Dr. Mohammad Hoesin in Palembang, Persahabatan Hospital in Jakarta, Dr. Hasan Sadikin Hospital in Bandung and Dr. Adam Malik Hospital in Medan.

This paper describes the measurement of dosimetric parameters for photon and electron beams of newly installed Elekta Precise Treatment System medical LINACs in order to implement the beam matching concept using the AGL program. This implementation of the beam matching concept is the first time in Indonesia.

\section{EXPERIMENTAL METHODS}

\section{Beam matching method}

By following the procedures provided by the manufacturer, measurements of complete dosimetric parameters have to be carried out to obtain the data of the first LINAC. Afterwards, the dosimetric parameter data of the first LINAC can be used as a reference for other LINACs. For the beam matching, the dosimetry characteristics of each LINAC have to be made equal or close to the reference LINAC.

Before the beam matching, each LINAC should perform individual primary commissioning to ensure their good performance. Then the step should be continued with the ATP and BDC procedures. For this reason, several beam measurements were carried out including percentage depth dose (PDD), beam profile, output factor, and wedge factor. All of the measurement data have to follow the limits given by the manufacturer's guidelines or recommendations issued through other credible publications. All TPS software installed for each LINACs will use the matched input data.

One method to verify the measurement results uses the gamma index ( $\gamma$-index), a parameter used to determine suitable dosimetry from two-dose distribution $[6,8,9]$. In this case, two-dose distribution has a definition that a pair of dose distribution obtained from dosimetry measurement among LINACs can be compared. It requires a datum used as a reference compared with other data. The two-dose distributions represent the same qualitative parameters, e.g., PDD and PDD, beam profiles, and beam profiles. 
Based on the reference [6], the best methods available for quantitative evaluation of the beam matching concept were based on the $\gamma$-index which consist "distance-to-agreement" (DTA) acceptance, and "dose-different" (DD). The methods used in this study are focused on fulfilling beam matching criteria.

The measurement result was compared to reference data that has been modeled by the Elekta manufacturer. As an example, the measurement results of LINAC serial number 109057 was compared with the reference LINAC as shown in Fig. 1.

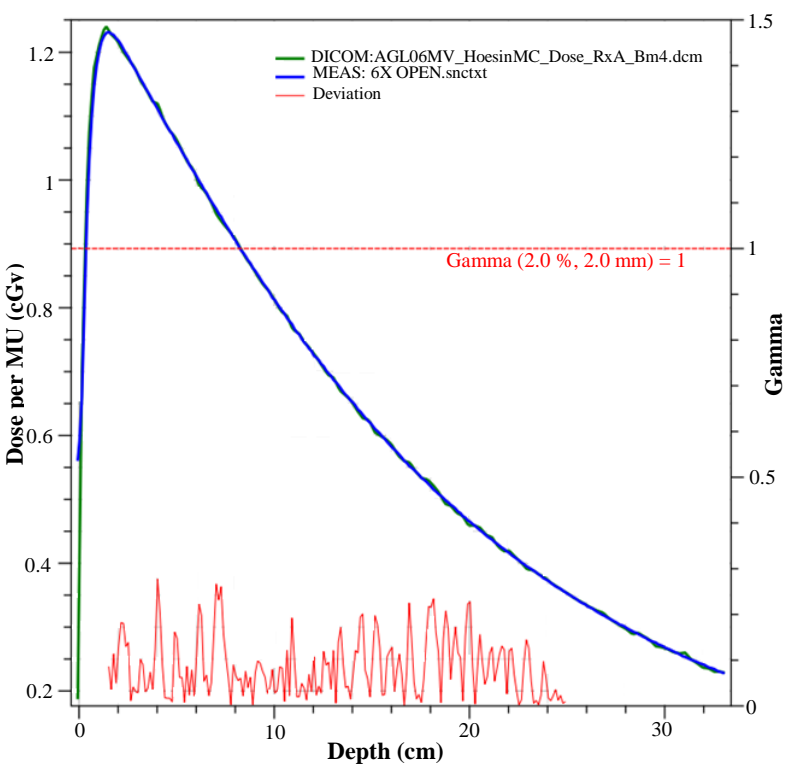

(a)

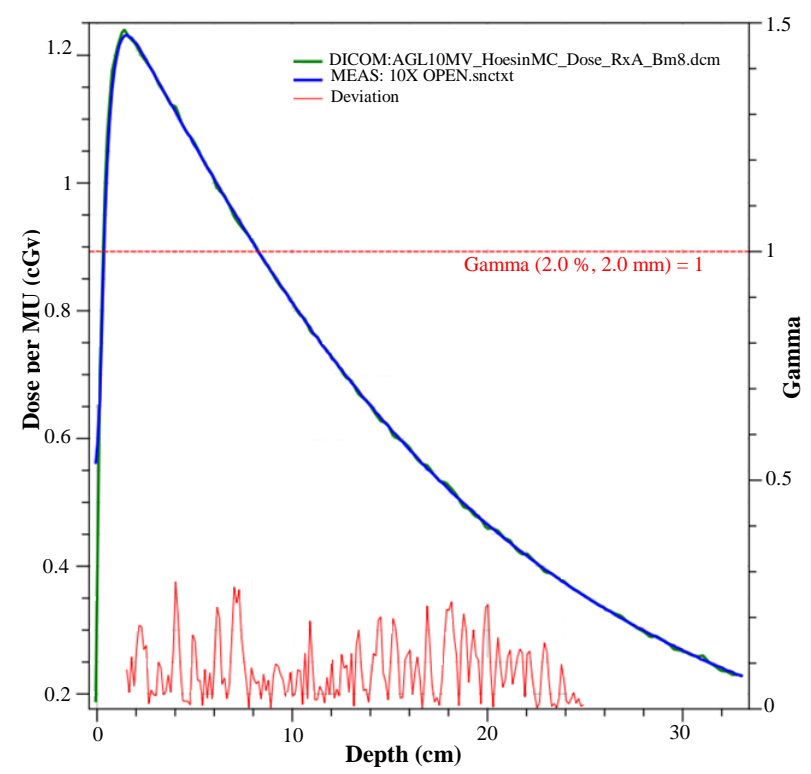

(b)

Fig. 1. The comparison result of PDD curve between; (a). $6 \mathrm{MV}$ photon beam; (b). $10 \mathrm{MV}$ photon beam for LINACs with serial number 109504 and 109057.

\section{Radiation source}

The radiation sources used were five units of Elekta Precise Treatment System medical LINACs with serial numbers of 109054, 109055, 109056, 109057 and 109058. The LINAC with serial number 109054 was used as referece for the implementation of the beam matching concept. All Elekta LINACs have 6 and $10 \mathrm{MV}$ photon beams and $4,6,9,12,15$, and $18 \mathrm{MeV}$ nominal energies of electron beams. For the use of electron beams, the LINACs were equipped with 6 applicators to form radiation field size of $6 \times 6 \mathrm{~cm}, 10 \times 10 \mathrm{~cm}$, $14 \times 6 \mathrm{~cm}, 14 \times 14 \mathrm{~cm}, 20 \times 20 \mathrm{~cm}$ and $25 \times 25 \mathrm{~cm}$. According to several references, the Elekta Precise Treatment System LINAC has been widely installed by institutions that have radiotherapy facilities both in Indonesia and abroad [10,11].

\section{Dosimeter used for measurement}

The beam measurement was carried out by using ionization chambers with relative and absolute methods. The relative method was performed by measuring the output factor, PDD, beam profile, and the wedge factor, while the absolute method was performed by measuring the absolute dose at reference conditions for calibration requirements $1 \mathrm{cGy} \approx 1 \mathrm{MU}$.

The ionization chamber used as dosimeter for relative measurement was the SNC125 type with active volume of $0.125 \mathrm{~cm}^{3}$ together with a cylinder water phantom "3D Scanner $^{\mathrm{TM}}$, manufactured by Sun Nuclear, which has a height of $67.3 \mathrm{~cm}$ and a width of $87.5 \mathrm{~cm}$, the electrometer of this dosimeter is a single package coupled with water phantom. The dosimeters used for field size under $3 \times 3 \mathrm{~cm}$ were ionization chamber of $0.6 \mathrm{~cm}^{3}$ type TW30013 and PTW Pinpoint 3D type TW30016 with volume of $0.016 \mathrm{~cm}^{3}$ coupled with a PTW Unidos Webline electrometer.

For photon absolute dose measurements, $0.6 \mathrm{~cm}^{3}$ ionization type TW30013 with PTW Unidos Webline electrometers were used. The measurements were perfomed in " $1 \mathrm{D}$ scanner" ${ }^{\mathrm{TM}}$, water phantom with dimension of $37 \times 40.6 \times$ $36.8 \mathrm{~cm}$.

The dosimeter used for electron beams were SNC350p parallel plate ionization chamber with an active volume of $0.388 \mathrm{~cm}^{3}$, and the PTW Roos $0.35 \mathrm{~cm}^{3}$ ionization chamber type TW34001. 
Table 1. Photon and electron beams data measurement condition.

\begin{tabular}{|c|c|c|c|c|c|}
\hline \multirow{2}{*}{$\begin{array}{l}\text { Beam } \\
\text { Type }\end{array}$} & \multirow{2}{*}{ Measurement } & \multirow{2}{*}{ Ionization chamber } & \multicolumn{3}{|c|}{ Condition } \\
\hline & & & SSD (cm) & Depth (cm) & Field Size $\left(\mathrm{cm}^{2}\right)$ \\
\hline \multirow{5}{*}{$\begin{array}{l}\text { Photon } \\
\text { beam }\end{array}$} & Absolute dose & Farmer $0.6 \mathrm{~cm}^{3}$ & 100 & 10 & $10 \times 10$ \\
\hline & Ouput factor at open field & $\begin{array}{l}\text { Farmer } 0.6 \mathrm{~cm}^{3} \text {, } \\
\text { PinPoint 3D } 0.016 \mathrm{~cm}^{3}\end{array}$ & 90 & 10 & $3 \times 3,5 \times 5,10 \times 10,30 \times 30$ \\
\hline & Wedge factor at open field & $\begin{array}{l}\text { Farmer } 0.6 \mathrm{~cm}^{3}, \\
\text { PinPoint 3D } 0.016 \mathrm{~cm}^{3}\end{array}$ & 90 & 10 & $10 \times 10$ \\
\hline & PDD at open field & $\mathrm{SNC} 1250.125 \mathrm{~cm}^{3}$ & 90 & 10 & $10 \times 10$ \\
\hline & $\begin{array}{l}\text { Beam profile (inline and } \\
\text { crossline) }\end{array}$ & $\mathrm{SNC} 1250.125 \mathrm{~cm}^{3}$ & 90 & 10 & $10 \times 10$ \\
\hline \multirow{4}{*}{$\begin{array}{l}\text { Electron } \\
\text { beam }\end{array}$} & Absolute dose & Roos $0.35 \mathrm{~cm}^{3}$ & 100 & 10 & $10 \times 10$ \\
\hline & Ouput factor at open field & $\begin{array}{l}\text { Farmer } 0.6 \mathrm{~cm}^{3} \text {, } \\
\text { PinPoint 3D } 0.016 \mathrm{~cm}^{3}\end{array}$ & 100 & 10 & $\begin{array}{l}6 \times 6,10 \times 10,14 \times 6 \\
14 \times 14,20 \times 20,25 \times 25\end{array}$ \\
\hline & PDD at open field & SNC125 $0.125 \mathrm{~cm}^{3}$ & 100 & 10 & $10 \times 10$ \\
\hline & $\begin{array}{l}\text { Beam profile (inline and } \\
\text { crossline) }\end{array}$ & $\mathrm{SNC} 1250.125 \mathrm{~cm}^{3}$ & 100 & 10 & $10 \times 10$ \\
\hline
\end{tabular}

\section{Scanning and measurement}

All scanning and relative measurements for photon beams data were carried out in water with source to surface distance $(\mathrm{SSD}) 90 \mathrm{~cm}$. The measurement of the absorbed dose to water was done at a depth of $10 \mathrm{~cm}\left(\mathrm{D}_{10}\right)$ with collimator angle of 0 degrees.

The scanning for the electron beams were performed with SSD of $100 \mathrm{~cm}$ at maximum depth $\left(D_{\max }\right)$. For the variation of field size requirement, electron applicator with several sizes were used, specifically $6 \times 6 \mathrm{~cm}, 10 \times 10 \mathrm{~cm}, 14 \times 6 \mathrm{~cm}$, $14 \times 14 \mathrm{~cm}, 20 \times 20 \mathrm{~cm}$, and $25 \times 25 \mathrm{~cm}$.

The absolute dose measurement per MU was carried out under reference conditions of $10 \times 10 \mathrm{~cm}$ field size, SSD of $100 \mathrm{~cm}$, and a depth of $10 \mathrm{~cm}$ $\left(\mathrm{D}_{10}\right)$. Calibration is needed to adjust $1 \mathrm{cGy} \approx 1 \mathrm{MU}$. This calibration applies for photon and electron beams.

The absolute measurements were carried out using the dosimetry protocol published by the International Atomic Energy Agency (IAEA), e.g., the Technical Report Series (TRS) No. 398. Measurement of the output factor, wedge factor, PDD, and radiation beam profile were carried out by following the AGL protocol as described in Table 1.

\section{RESULTS AND DISCUSSION}

\section{The result of PDD of the photon beam measurement}

The results of PDD measurements for all the installed medical LINACs can be seen in Table 2. It is shown that the obtained $\mathrm{PDD}_{10}$ for $6 \mathrm{MV}$ photon beam of other LINACs have a maximum deviation of $0.4 \%$ against the $\mathrm{PDD}_{10}$ of the reference LINAC with serial number 109054 .

Table 2. The measurement results of $\mathrm{PDD}_{10}$ for 6 and $10 \mathrm{MV}$ photon beam.

\begin{tabular}{ccc}
\hline \multirow{2}{*}{ LINAC serial number } & \multicolumn{2}{c}{ PDD $_{\mathbf{1 0}}(\boldsymbol{\%})$} \\
\cline { 2 - 3 } & Photon 6 MV & Photon 10 MV \\
\hline 109054 & 67.69 & 72.98 \\
109056 & 67.42 & 72.66 \\
109057 & 67.40 & 72.68 \\
109055 & 67.49 & 72.94 \\
109058 & 67.99 & 73.01 \\
\hline
\end{tabular}

Figure 1 illustrates the comparison results between the measured PDD curve and the PDD modeled from the reference LINAC. The red graph was the result of the deviation from the comparison of the two PDDs. The maximum deviation for the $6 \mathrm{MV}$ photon beam was not higher than $0.5 \%$, while for the $10 \mathrm{MV}$ photon beam, the maximum deviation was less than $0.8 \%$. Both of the maximum deviations were still below $1 \%$.

The parameter presented in Fig. 1 is the gamma index ( $\gamma$-index). The $\gamma$-index parameter in the $6 \mathrm{MV}$ and $10 \mathrm{MV}$ photon beam comparison has a good fit, which is $2 \%$ of DD, 2 mm of DTA. It follow the data requirements for the beam matching process.

\section{Photon beam profile}

The measurement results for $6 \mathrm{MV}$ and $10 \mathrm{MV}$ photon beam profiles of the 
Elekta Precise LINACs can be seen in Table 3 .

Table 3. The results of beam profile measurements for 6 and $10 \mathrm{MV}$ photon beam of installed Elekta LINACs.

\begin{tabular}{llcccc}
\hline \multirow{2}{*}{$\begin{array}{c}\text { LINAC } \\
\text { serial } \\
\text { number }\end{array}$} & Parameter & \multicolumn{2}{c}{ Photon 6 MV } & \multicolumn{2}{c}{ Photon 10 MV } \\
\cline { 3 - 6 } & Inline & $\begin{array}{c}\text { Cross- } \\
\text { line }\end{array}$ & Inline & $\begin{array}{c}\text { Cross- } \\
\text { line }\end{array}$ \\
\hline \multirow{2}{*}{109054} & Flatness & 104.77 & 105.23 & 103.83 & 105.72 \\
& Symmetry & 101.17 & 100.69 & 100.24 & 101.01 \\
109056 & Flatness & 104.27 & 105.13 & 104.35 & 105.13 \\
& Symmetry & 100.29 & 100.24 & 100.07 & 100.24 \\
\multirow{2}{*}{109057} & Flatness & 104.49 & 105.62 & 104.28 & 105.19 \\
& Symmetry & 101.08 & 101.70 & 100.86 & 100.37 \\
109055 & Flatness & 104.48 & 105.68 & 104.51 & 105.38 \\
& Symmetry & 101.07 & 100.30 & 100.98 & 100.64 \\
109058 & Flatness & 104.15 & 105.02 & 104.25 & 105.05 \\
& Symmetry & 100.30 & 100.89 & 100.80 & 100.49 \\
\hline
\end{tabular}

Based on Table 3, the maximum deviation in the results of the four LINACs against the reference LINAC data was $5.7 \%$ and $1.7 \%$, respectively, for flatness and symmetry $6 \mathrm{MV}$ photon beam. The acceptable deviation range for the flatness is $6 \%$, while the symmetry was $3 \%$ for the value of 100.00 in both the inline or crossline profiles.

Figure 2 shows the deviation in the measurement of the $6 \mathrm{MV}$ photon radiation beam profile on the $\mathrm{X}$-axis and $\mathrm{Y}$-axis. The deviation for measurements on the $\mathrm{X}$-axis were less than $0.3 \%$, and on the $\mathrm{Y}$-axis were less than $0.2 \%$. The $\gamma$-index parameter obtained by the two graphs shows that the acceptance matches the requirements of the beam matching data, which is $3.0 \%$ of DD, $3 \mathrm{~mm}$ of DTA.

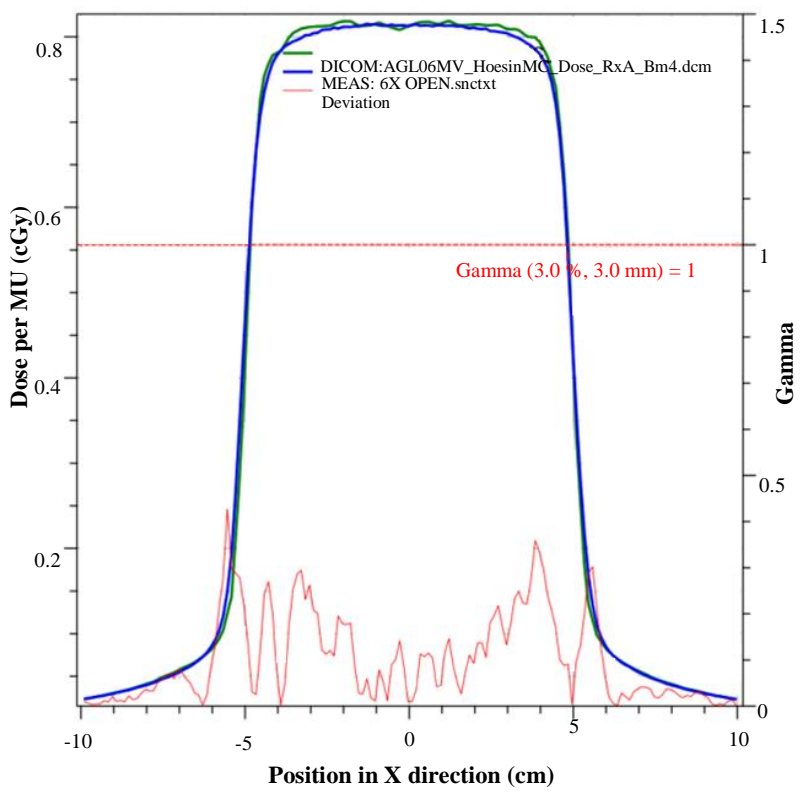

(a)

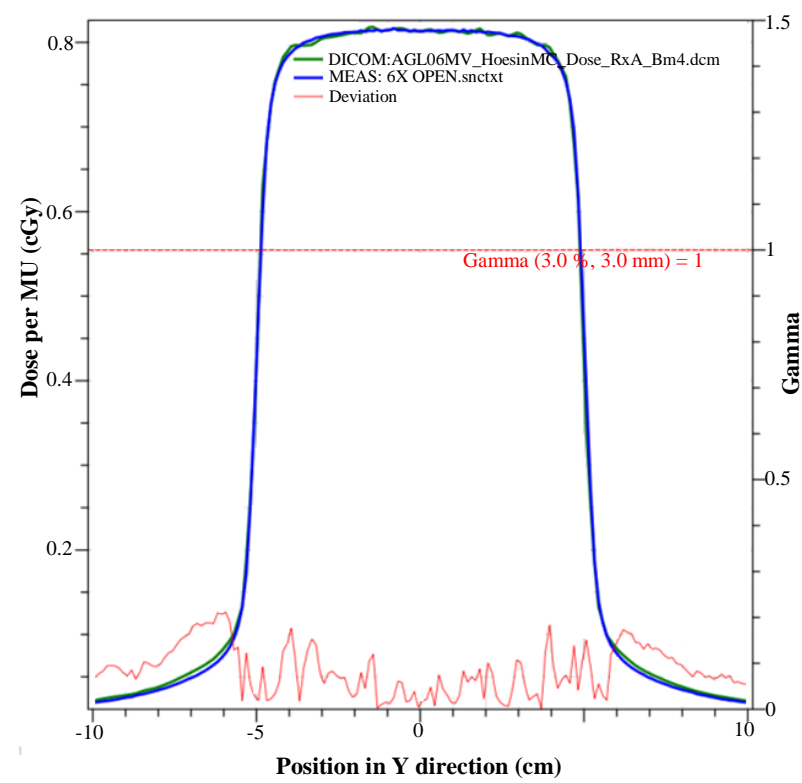

(b)

Fig. 2. The results of comparison between the reference LINAC serial number 109504 and 109507 in 6 MV Photon beam position; (a). in $\mathrm{X}$ direction and; (b). in Y direction.

\section{Output factor}

The results of output factor measurements at field sizes of $3 \times 3 \mathrm{~cm}$ up to $30 \times 30 \mathrm{~cm}$ are shown in Table 4 for $6 \mathrm{MV}$ photon beam and Table 5 for $10 \mathrm{MV}$ photon beam.

Table 4. The results of output factor measurement for $6 \mathrm{MV}$ photon beam.

\begin{tabular}{ccccc}
\hline \multirow{2}{*}{$\begin{array}{c}\text { LINAC serial } \\
\text { number }\end{array}$} & \multicolumn{4}{c}{ Field size } \\
\cline { 2 - 5 } & $\mathbf{3 \times 3}$ & $\mathbf{5 \times 5}$ & $\mathbf{1 0} \times \mathbf{1 0}$ & $\mathbf{3 0 \times 3 0}$ \\
\hline 109054 & 0.845 & 0.902 & 1.000 & 1.147 \\
109056 & 0.845 & 0.907 & 1.000 & 1.129 \\
109057 & 0.843 & 0.901 & 1.000 & 1.156 \\
109055 & 0.844 & 0.902 & 1.000 & 1.157 \\
109058 & 0.846 & 0.904 & 1.000 & 1.155 \\
\hline
\end{tabular}

It can be seen that the four LINACs have maximum deviation of $1.6 \%$ for 6 MV photon beam, and $0.9 \%$ for 10 MV photon beam, respectively, to the reference LINAC. As the deviation limit for the output factor parameter to the reference LINAC is $2 \%$, the obtained measurement data are within the acceptable range. 
Table 5. The results of output factor measurement for $10 \mathrm{MV}$ photon beam.

\begin{tabular}{ccccc}
\hline \multirow{2}{*}{$\begin{array}{c}\text { LINAC serial } \\
\text { number }\end{array}$} & $\mathbf{3} \times \mathbf{3}$ & $\mathbf{5 \times 5}$ & $\mathbf{1 0} \times \mathbf{1 0}$ & $\mathbf{3 0} \times \mathbf{3 0}$ \\
\cline { 2 - 5 } & 0.864 & 0.920 & 1.000 & 1.114 \\
109054 & 0.864 & 0.921 & 1.000 & 1.107 \\
109056 & 0.862 & 0.917 & 1.000 & 1.123 \\
109057 & 0.862 & 0.918 & 1.000 & 1.124 \\
109055 & 0.864 & 0.917 & 1.000 & 1.122 \\
109058 & & & & \\
\hline
\end{tabular}

\section{Wedge factor}

The results of wedge factor measurements for 6 and $10 \mathrm{MV}$ photon beams is shown in Table 6. It appears that the maximum deviation is $0.9 \%$ respected to the reference LINAC data. The deviation limit for wedge factor parameters to reference LINAC is $1 \%$; thus, the obtained data is in the acceptable range.

Table 6. The result of wedge factor measurements for 6 and 10 MV photon beams.

\begin{tabular}{ccc}
\hline $\begin{array}{c}\text { LINAC serial } \\
\text { number }\end{array}$ & Photon 6 MV & Photon 10 MV \\
\hline 109054 & 0.265 & 0.279 \\
109056 & 0.267 & 0.281 \\
109057 & 0.266 & 0.281 \\
109055 & 0.266 & 0.279 \\
109058 & 0.266 & 0.282 \\
\hline
\end{tabular}

\section{Photon output}

The results of output calibration for 6 and 10 MV photon beams measured under the reference conditions, e.g. SSD $100 \mathrm{~cm}$ and field size $10 \mathrm{~cm} \times 10 \mathrm{~cm}$ is shown in Table 7 . Apparently, there are no significant deviation among the five LINACs.

Table 7. The results of output calibration for 6 and $10 \mathrm{MV}$ photon beams.

\begin{tabular}{|c|c|c|}
\hline \multirow{2}{*}{ LINAC serial number } & Photon 6 MV & Photon $10 \mathrm{MV}$ \\
\hline & \multicolumn{2}{|c|}{ Dose (mGy/200MU) } \\
\hline 109054 & 2011 & 2008 \\
\hline 109056 & 2003 & 2002 \\
\hline 109057 & 2002 & 1989 \\
\hline 109055 & 2001 & 2010 \\
\hline 109058 & 2010 & 2005 \\
\hline
\end{tabular}

\section{The result of PDD of the electron beam measurement}

The measurement results of the PDD electron beam with nominal energy of $4,6,8,10$, 15 , and $18 \mathrm{MeV}$ is shown in Table 8 .

It can be seen that the four LINACs have maximum deviation results for $1 \mathrm{~mm}$ in $R_{80}$ against the reference LINAC. This results suggest that the quality of the electron beam from the installed LINACs are nearly equal.

Table 8. The measurement results of PDD of the electron beam for $\mathrm{R}_{80}$ for installed LINACs.

\begin{tabular}{ccccccc}
\hline \multirow{2}{*}{$\begin{array}{c}\text { LINAC } \\
\text { serial } \\
\text { number }\end{array}$} & \multicolumn{6}{c}{ Nominal Energy (MeV) } \\
\cline { 2 - 7 } & $\mathbf{4}$ & $\mathbf{6}$ & $\mathbf{8}$ & $\mathbf{1 0}$ & $\mathbf{1 5}$ & $\mathbf{1 8}$ \\
\hline 109054 & 1.369 & 2.059 & 2.668 & 3.253 & 4.947 & 6.009 \\
109056 & 1.371 & 2.051 & 2.673 & 3.275 & 4.983 & 6.021 \\
109057 & 1.377 & 2.043 & 2.691 & 3.290 & 4.975 & 5.989 \\
109055 & 1.375 & 2.072 & 2.715 & 3.355 & 4.975 & 5.993 \\
109058 & 1.363 & 2.025 & 2.675 & 3.304 & 5.004 & 6.036 \\
\hline
\end{tabular}

\section{Electron beam profile}

The measurement results of the electron beam profile at SSD of $10 \mathrm{~cm}$ using standard electron applicator of $10 \mathrm{~cm} \times 10 \mathrm{~cm}$ is shown in Table 9 and Table 10.

Table 9. The measurement results of beam profile flatness and symmetry for 4,6 , and $8 \mathrm{MeV}$ electron beams.

\begin{tabular}{|c|c|c|c|c|c|c|c|}
\hline \multirow{2}{*}{$\begin{array}{c}\text { LINAC } \\
\text { serial } \\
\text { number }\end{array}$} & \multirow{2}{*}{ F/S } & \multicolumn{2}{|c|}{$4 \mathrm{MeV}$} & \multicolumn{2}{|c|}{$6 \mathrm{MeV}$} & \multicolumn{2}{|c|}{$8 \mathrm{MeV}$} \\
\hline & & In & Cross & In & Cross & In & Cross \\
\hline \multirow{2}{*}{109054} & Flat & 100.19 & 100.09 & 100.19 & 100.20 & 100.13 & 100.07 \\
\hline & Sym & 102.46 & 100.66 & 101.04 & 100.38 & 100.47 & 100.39 \\
\hline \multirow{2}{*}{109056} & Flat & 103.25 & 102.06 & 100.09 & 100.17 & 100.06 & 100.35 \\
\hline & Sym & 100.41 & 102.99 & 100.36 & 100.59 & 100.31 & 100.67 \\
\hline \multirow{2}{*}{109057} & Flat & 100.09 & 100.10 & 100.15 & 100.10 & 100.13 & 100.12 \\
\hline & Sum & 10044 & 10061 & 10047 & 10048 & 10048 & 10050 \\
\hline \multirow{2}{*}{109055} & Flat & 100.09 & 100.08 & 100.12 & 100.06 & 100.12 & 100.13 \\
\hline & Sym & 100.29 & 100.64 & 100.56 & 100.22 & 100.33 & 100.33 \\
\hline \multirow{2}{*}{109058} & Flat & 102.84 & 102.38 & 103.52 & 103.36 & 102.70 & 102.69 \\
\hline & Sym & 100.22 & 100.11 & 100.82 & 101.01 & 100.81 & 100.65 \\
\hline
\end{tabular}


Table 10. The measurement results of beam profile flatness and symmetry for 10,15 , and $18 \mathrm{MeV}$ electron beam.

\begin{tabular}{cccccccc}
\hline $\begin{array}{c}\text { LINAC } \\
\text { serial } \\
\text { number }\end{array}$ & F/S & \multicolumn{2}{c}{$10 \mathrm{MeV}$} & \multicolumn{2}{c}{$15 \mathrm{MeV}$} & \multicolumn{2}{c}{$18 \mathrm{MeV}$} \\
\cline { 3 - 8 } & In & Cross & In & Cross & In & Cross \\
\hline \multirow{2}{*}{109054} & Flat & 100.13 & 100.34 & 100.54 & 100.57 & 100.64 & 100.4 \\
& Sym & 101.01 & 101.24 & 101.84 & 102.34 & 102.06 & 101.55 \\
& Flat & 100.09 & 100.15 & 100.09 & 100.14 & 100.03 & 100.17 \\
109056 & Sym & 100.27 & 100.77 & 100.41 & 100.49 & 100.55 & 100.59 \\
& Flat & 100.10 & 100.09 & 100.11 & 100.11 & 100.08 & 100.11 \\
109057 & Sym & 100.27 & 100.23 & 100.48 & 100.27 & 100.59 & 101.03 \\
& Flat & 100.08 & 100.16 & 100.06 & 100.18 & 100.06 & 100.11 \\
109055 & Sym & 100.56 & 101.33 & 100.40 & 100.51 & 100.33 & 101.86 \\
& Flat & 102.57 & 102.53 & 102.88 & 102.33 & 102.65 & 102.64 \\
109058 & Sym & 100.85 & 100.81 & 100.80 & 101.11 & 101.58 & 101.39 \\
\hline
\end{tabular}

The maximum deviation for the four LINACs to the reference LINAC are $3.3 \%$ and $2.3 \%$, respectively, for flatness and symmetry of electron beams. The radiation beam profile data are within the acceptable range.

\section{Output factor}

The measurement results of electron output factor are displayed in Table 11 for reference LINAC. Meanwhile, the output factor for other LINACs are in a good agreement within $2 \%$ of deviation limit. However, there are some deviations of more than $2 \%$ for several nominal energies. The maximum deviation obtained are within in range of 3-5\%.

Table 11. The measurement results of output factor for the reference LINAC.

\begin{tabular}{lcccccc}
\hline \multirow{2}{*}{ Applicator } & \multicolumn{6}{c}{ Nominal Energy (MeV) } \\
\cline { 2 - 7 } & $\mathbf{4}$ & $\mathbf{6}$ & $\mathbf{8}$ & $\mathbf{1 0}$ & $\mathbf{1 5}$ & $\mathbf{1 8}$ \\
\hline $6 \times 6$ & 0.784 & 0.925 & 0.954 & 0.986 & 0.977 & 0.986 \\
$10 \times 10$ & 1.000 & 1.000 & 1.000 & 1.000 & 1.000 & 1.000 \\
$14 \times 6$ & 0.873 & 0.961 & 0.972 & 0.982 & 0.987 & 0.994 \\
$14 \times 14$ & 1.000 & 1.000 & 0.991 & 0.986 & 0.982 & 0.985 \\
$20 \times 20$ & 0.995 & 1.016 & 0.997 & 0.977 & 0.976 & 0.976 \\
$25 \times 25$ & 1.010 & 1.021 & 1.006 & 0.989 & 0.991 & 0.978 \\
\hline
\end{tabular}

\section{Electron output}

The measurement results of the output calibration of the electron beam at SSD of $100 \mathrm{~cm}$ using standard electron applicator of $10 \times 10 \mathrm{~cm}$ can be seen in Table 12 which all of the electron output within acceptable range for $1 \mathrm{cGy} \approx 1 \mathrm{MU}$.

Table 12. The measurement results of the output calibration of the electron beam for installed LINACs.

\begin{tabular}{ccccccc}
\hline LINAC & \multicolumn{6}{c}{ Dose (mGy/200MU) } \\
\cline { 2 - 7 } $\begin{array}{c}\text { serial } \\
\text { number }\end{array}$ & $\begin{array}{c}\mathbf{4} \\
\mathbf{M e V}\end{array}$ & $\begin{array}{c}\mathbf{M} \\
\mathbf{M e V}\end{array}$ & $\begin{array}{c}\mathbf{8} \\
\mathbf{M e V}\end{array}$ & $\begin{array}{c}\mathbf{1 0} \\
\mathbf{M e V}\end{array}$ & $\begin{array}{c}\mathbf{1 5} \\
\mathbf{M e V}\end{array}$ & $\begin{array}{c}\mathbf{1 8} \\
\mathbf{M e V}\end{array}$ \\
\hline 109054 & 1993 & 2001 & 2002 & 2003 & 2004 & 2000 \\
109056 & 1996 & 2004 & 1998 & 1994 & 1991 & 1999 \\
109057 & 2002 & 2001 & 1997 & 1995 & 1998 & 2001 \\
109055 & 1994 & 2000 & 2002 & 2001 & 2002 & 2000 \\
109058 & 2001 & 2001 & 2001 & 2001 & 2000 & 1998 \\
\hline
\end{tabular}

\section{Discussion}

The beam matching concept has commonly implemented in radiotherapy facility that installs more than one LINAC unit from the same manufacturer, type, and features such as multi-leaf collimator (MLC). This implementation is essential for efficiency and effectiveness, considering that beam data collection (BDC) during LINAC installation requires quite a long time.

The implementation of the beam matching concept to five LINAC have been carried out and the obtained results follow the acceptance requirements set by the Elekta LINAC manufacturer. The implementation has been done based on the Elekta's Accelerated Go Live (AGL) manual document.

The approach for the implementation of the beam matching concept used in this study was to choose a LINAC as a reference and the data of other LINACs were adjusted based on the reference LINAC. Adjustments of hardware or software can be undertaken during installation of the LINACs.

The criteria used for the beam matching acceptance were based on the suitability of dose percentage graph in-depth and radiation beam profile [12]. The evaluated dosimetry beam data of the beam-matched LINACs show their similar dosimetry characteristics. The measurement results for the five LINACs give acceptable deviation in the range of $1 \%, 6 \%$, and $3 \%$ for respectively the PDD, flatness, and symmetry of the radiation beam profiles.

The output factor measurements were undertaken at the installation site and the results were sent to the manufacturer for beam model adjustments. However, this output factor is not the main parameter for adjustment among the LINACs. The output factor data can be adjusted manually at the TPS, in accordance to the modeling that has been obtained [8]. 
The measurement results of the electron beam output factor for four unit LINACs show some deviation within $2 \%$. There were some deviation of more than $2 \%$ for several nominal energy and LINACs. The maximum deviation is in a range of $3-5 \%$. This is considered in a good agreement because the output factor can be adjusted on site.

The verification carried out by the Elekta manufacturer for the PDD parameters uses $\gamma$-index of $2 \%$ of DD and $2 \mathrm{~mm}$ of DTA, while for the radiation beam profile of $3 \%$ of DD and $3 \mathrm{~mm}$ of DTA. It has a definition of suitability for comparing the two dosimetry data having a maximum dose-difference requirement of $2 \%$ and a distance-to-agreement range of $2 \mathrm{~mm}$ for the PDD. Likewise, the value of the radiation beam profile has an $\gamma$-index of $3 \%$ of DD and $3 \mathrm{~mm}$ of DTA.

If something goes wrong with one LINAC, and the data is not suitable with the $\gamma$-index parameter, the Elekta manufacturer will confirm to repeat the measurement, and adjust the LINACs until the parameters are in good agreement.

The beam output of the LINAC was known to be insignificantly different, for both the photon and the electron beams. During the output calibration process, the photon and electron beams that was not under the conditions of $1 \mathrm{cGy} \approx 1 \mathrm{MU}$ can be adjusted directly, using software to recalibrate the output. Usually, the output of the LINAC will be stable at $\pm 2 \%$ for $1 \mathrm{cGy} \approx 1 \mathrm{MU}$ by proper maintenance and routine calibration [9].

The implementation of the beam matching concept to several LINACs should be accompanied by adequate maintenance and Quality Assurance (QA) processes, to ensure the suitability of dosimetry parameters among the LINACs. There is a published paper discussing QA in beam matched LINAC for several tumor case data $[8,9]$.

Therefore the authors recommends that further study need to be undertaken on QA for the five LINACs that have been matched in a certain period [13]. Also reviews about clinical practices with the beam matched LINACs should be undertaken for several tumor cases $[14,15]$. Data from these studies may be referred for maintainance recommendations as well as for adjusting LINACs performance to the matching concept.

The authors also recommend to study the suitability of the TPS calculations with independent verification using software that can simulate photons and electron transport such as Monte Carlo code to verify the beam matching concept [16].

\section{CONCLUSION}

It can be concluded that the beam matching concept has been implemented for five units Elekta Precise treatment System LINACs. The dosimetry parameters that required by Elekta manufacturer for beam modeling were the percentage depth dose (PDD) and radiation beam profiles, while other dosimetry parameters such as wedge factors, output factors, and absolute doses can be inputted after the LINAC modeling has completed. The obtained measurement results of the dosimetry parameters meet the requirements set by the Elekta manufacturer for the beam matching process.

The ATP and BDC process could be shortened by implementing this method, and the LINAC facilities could be clinically operated earlier compared to using conventional method. On the other hand, a few matched LINACs facilities could save more patients in case of effectiveness the medical physicist does not need to do re-planning if the patient would change the facilities.

\section{ACKNOWLEDGEMENT}

The author would like to acknowledge to staffs of the radiotherapy unit of Sanglah Central General Hospital Denpasar Bali, Central General Hospital Dr. Mohammad Hoesin in Palembang, Persahabatan Hospital in Jakarta, Dr. Hasan Sadikin in Bandung and Hospital Dr. Adam Malik in Medan for their valuable helps.

\section{AUTHOR CONTRIBUTION}

Okky Agassy Firmansyah contributed as the main contributor to this paper. All authors read and approved the final version of the paper.

\section{REFERENCES}

1. M. A. Reza, M. R. Islam, M. S. Rahman et al., Int. Lett. Chem. Phys. Astron. 79 (2018) 1.

2. D. van der Merwe, J. Van Dyk, B. Healy et al., Acta Oncol. 56 (2017) 1.

3. S. Ashokkumar, K. M. Ganesh, K. Ramalingam et al., Asian Pac. J. Cancer Prev. 18 (2017) 3439.

4. E. M. Attalla, H. S. Abou-Elenein, H. Ammar et al., Chinese-German J. Clin. Oncol. 13 (2014) 89. 
5. T. Kairn, A. Asena, P. H. Charles et al, Australas. Phys. Eng. Sci. Med. 38 (2015) 289.

6. J. R. Bhangle, V. K. S. Narayanan, N. K. Kumar et al., J. Med. Phys. 36 (2011) 176.

7. Z. Xu, G. Warrell, S. Lee et al., J. Appl. Clin. Med. Phys. 20 (2019) 68.

8. J. Gagneur and G. Ezzell, Med. Phys. 40 (2013) 491.

9. J. Rijken, H. Schachenmayr, S. Crowe et al., J. Appl. Clin. Med. Phys. 20 (2019) 99.

10. F. Shahedi, M. Momennezhad, S. Naseri et al., Iran. J. Med. Phys. 15 (2018) 295.
11. F. Padilla-Cabal, M. Pérez-Liva, E. Lara et al., J. Radiother. Pract. 14 (2015) 311.

12. C. Krishnappan, C. A. Radha, V. Subramani et al., J. Appl. Clin. Med. Phys. 17 (2016) 111.

13. D. Sjöström, U. Bjelkengren, W. Ottosson et al., Acta Oncol. 48 (2009) 192.

14. M. A. Bolt, C. H. Clark, T. Chen et al., Phys. Imaging Radiat. Oncol. 4 (2017) 39.

15. C. Krishnappan, C. A. Radha, K. Balaji et al., Radiol. Phys. Technol. 11 (2018) 423.

16. S. Kang, J. B. Chung, K. Y. Eom et al., J. Korean Phys. Soc. 75 (2019) 628. 